\title{
Serum 14-3-3 $\beta$ Protein: a New Biomarker in Asthmatic Patients With Acute Attack
}

\section{Decai Wang}

Guilin Medical University Affiliated Hospital

\section{Lizong Rao}

Guilin Medical University Affiliated Hospital

\section{Yalan Cui}

Guilin Medical University

\section{Guoting Tang}

Guilin Medical University Affiliated Hospital

\section{Haiming Huang}

Guilin Medical University Affiliated Hospital

\section{Ting Yuan}

Guilin Medical University Affiliated Hospital

Biwen Mo ( $\sim$ mobiwen2002@sohu.com )

Guilin Medical University Affiliated Hospital https://orcid.org/0000-0001-7726-3149

\section{Research}

Keywords: Asthma, Biomarker, 14-3-3 $\beta$

Posted Date: May 13th, 2021

DOI: https://doi.org/10.21203/rs.3.rs-508436/v1

License: (c) (i) This work is licensed under a Creative Commons Attribution 4.0 International License.

Read Full License 


\title{
Serum 14-3-3 $\beta$ protein: a new biomarker in asthmatic patients with acute attack
}

Decai Wang ${ }^{1}$, Lizong Rao ${ }^{1}$, Yalan Cui ${ }^{2}$, Guoting Tang ${ }^{1}$, Haiming Huang ${ }^{1}$, Ting Yuan ${ }^{1}$ and Biwen $\mathrm{Mo}^{1 *}$

*Correspondence: mobiwen2002@sohu.com

${ }^{1}$ Department of Respiratory and Critical Care Medicine, Affiliated Hospital of Guilin Medical University, Guangxi Zhuang Autonomous Region Education Department Key Laboratory of Respiratory Diseases, Guilin, Guangxi, China.

${ }^{2}$ Department of Anatomy, Guilin Medical University, Guilin, Guangxi, China.

\begin{abstract}
Background: The determination of systemic inflammatory markers is one of the important directions to study the pathogenesis of asthma and improve the diagnosis of asthma. Current studies have found that the 14-33 protein family subtypes interact with target proteins to participate in the pathogenesis of a variety of immune inflammatory diseases. However, studies on serum tyrosine3-monooxygenase/tryptophan5-monooxygenase activation protein $\beta$ (14-3-3 $\beta$ ) in asthma are scarce. This study aimed to assess the clinical significance of 14-3-3 $\beta$ in asthmatic patients.
\end{abstract}

Methods: We recruited 54 asthmatic patients with acute attack and 50 asthmatic patients with chronic persistent. The normal control group 
included 54 healthy individuals with similar sex-age indicators. Clinical characteristics (age, gender, height and weight), clinical indicators [fractional expiratory nitric oxide (FeNO), eosinophil count, forced vital capacity (FVC), percent of predicted FVC (FVC \% predicted), forced expiratory volume in one second (FEV1), percent of predicted FEV1 (FEV1\% predicted), the ratio of forced expiratory volume in one second to forced vital capacity (FEV1/FVC) and percent of predicted FEV1/FVC (FEV1/FVC\% predicted)] and serum 14-3-3 $\beta$ levels were measured to compare among each group. Spearman's rank correlation coefficient was

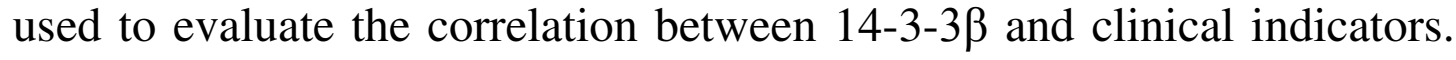
Finally, Receiver-operating characteristic (ROC) curves analysis was used to determine the sensitivity and specificity of $14-3-3 \beta$.

Results: Our results showed that median (interquartile range) of serum 14$3-3 \beta$ concentration $(\mathrm{ng} / \mathrm{ml})$ in acute attack group of asthma (41.18 [33.0651.76]) was much higher than that in normal control group (24.99 [17.4329.91]; $P<0.001)$ and chronic persistent group of asthma (25.88 [21.0334.55]; $P<0.001$ ), however, it was that exist no statistical heterogeneity with regard to the serum 14-3-3 $\beta$ level between the chronic persistent group of asthma and the healthy individuals $(P>0.05)$. Spearman's correlation coefficient shows that the serum 14-3-3 $\beta$ level was positively correlated with $\mathrm{FeNO}(\mathrm{r}=-0.292, P=0.032)$ and peripheral blood eosinophil 
count $(\mathrm{r}=0.328, P=0.016)$, and was negatively related to FEV1/FVC ( $\mathrm{r}=-$ 0.293, $P=0.031)$ and FEV1/FVC\% predicted $(\mathrm{r}=-0.299, P=0.028)$ in the acute attack group of asthma. At the same time, the serum 14-3-3 $\beta$ level was also negatively associated with FEV1 $(\mathrm{r}=-0.297, P=0.036)$ in the chronic persistent group of asthma. ROC curve analysis comparing acute attack group of asthma with normal control group demonstrated a significant $(P<0.001)$ AUC of 0.90 (95\% CI, 0.85-0.96). When the cut off value was $29.70 \mathrm{ng} / \mathrm{ml}$, the ROC curve yielded a sensitivity of $92.6 \%$, a specificity of $75.9 \%$, a positive likelihood ratio (+LR) of 3.84 , negative likelihood ratio (-LR) of 0.10 and a Youden index of 0.69 in acute attack group of asthma. ROC curve analysis comparing chronic persistent group of asthma with normal control group demonstrated no statistically significant difference $(P>0.05)$ AUC of 0.60 (95\% CI, 0.49-0.70).

Conclusion: The Elevated serum 14-3-3 $\beta$ levels may be associated with airway inflammation and impaired bronchial patency in the acute attack of asthma. The serum 14-3-3 $\beta$ protein can be used to distinguish between asthmatic patients with acute attack and healthy individuals and may become a potential biomarker in asthmatic patients with acute attack.

Keywords: Asthma, Biomarker, 14-3-3 $\beta$ 


\section{Background}

Asthma is a very common chronic airway disease leading to shortness of breath, chest tightness, and cough [1]. It is characterized by activation of mast cells and T-helper type 2 cells and eosinophil infiltration in the airway [2]. Symptoms fluctuate over time and can worsen and lead to respiratory failure during periods of exacerbation, which are often precipitated by viral upper respiratory tract infections or less commonly by exposure to aeroallergens or air pollution. It affects more than 300 million people globally, including 26 million in the United States [3]. Asthma causes substantial health and economic burdens, with more than 0.19 deaths per 100000 people in the world each year [4]. Currently, diagnosis and treatment of asthma are often based on symptoms and lung function test results [5]. However, these may not be able to predict future exacerbation. In addition, many primary care facilities are not equipped with spirometry to perform the necessary tests. Hence, identifying new biomarkers that can enhance the detection rate in patients with asthma has been a hot research topic.

The $14-3-3$ protein family is constituted by $28-33 \mathrm{kDa}$ acidic proteins [6] found in all eukaryotes that play a critical role in the regulation of intracellular functions including protein synthesis, cellular metabolism, protein trafficking, signal transduction, and cytoskeletal transport [7-9]. In mammalian cells, $14-3-3$ protein has seven isoforms $(\alpha / \beta, \varepsilon, \eta, \gamma, \sigma, \theta / \tau$, 
and $\delta / \zeta)$, with $\alpha$ and $\delta$ representing the phosphorylated versions of $\beta$ and $\zeta$, respectively $[10,11]$. The $14-3-3$ protein family is a class of proteins able to interact with a multitude of targets by establishing protein-protein interactions (PPIs) [8]. Previous many evidences show that misregulation of 14-3-3 proteins contributes to important human diseases such as cancer, neurodegenerative disorders, and infection by Giardia intestinalis [1215].However, Current studies have found that the 14-3-3 protein family subtypes interact with target proteins to participate in the pathogenesis of varieties of autoimmune disease including rheumatoid arthritis, systemic sclerosis, and large vessel vasculitis [16-18]. Furthermore, Li et al. [19] found that upregulating 14-3-3 $\sigma$ can enhance IgE class switching and antibody secretion of B cells in asthma model of miR146a overexpressing mice, which increases in $\operatorname{IgE}$ are linked with worsened asthma severity. More importantly, one study reported that $14-3-3 \beta$ mRNA is overexpressed in rat asthma models [20].

Based on these findings, we hypothesized that $14-3-3 \beta$ protein is elevated in asthmatic patients, especially in acute attack of asthma. To test our hypothesis, we conducted an observational study to measure 14-3-3 $\beta$ levels in asthmatic subgroup and normal control group. Furthermore, the relationship of serum 14-3-3 $\beta$ with clinical indicators [FeNO, eosinophil count, forced vital capacity (FVC), percent of predicted FVC (FVC \% predicted), forced expiratory volume in one second (FEV1), percent of 
predicted FEV1 (FEV1\% predicted), the ratio of forced expiratory volume in one second to forced vital capacity (FEV1/FVC) and percent of predicted FEV1/FVC (FEV1/FVC\% predicted)] was also analysed. Finally, in order to evaluate the diagnostic performance of $14-3-3 \beta$ protein in patients with asthma, we performed ROC curve analysis between asthmatic subgroup and normal control group.

\section{Materials and Methods}

\section{Patients with asthma and controls}

The present study was an observational study that included 104 patients who fulfilled the diagnostic criteria for asthma according to the Global Initiative for Asthma (GINA) [21]. All patients were recruited from the Department of Respiratory and Critical Care Medicine, Affiliated Hospital of Guilin Medical University from June 2019 to October 2020. Patients with asthma were further classified according to Guidelines for bronchial asthma prevent and management in China [22] into acute attack group with newly diagnosed asthma who had not yet received any treatment and chronic persistent group with established diagnosed asthma who was receiving treatment of Inhaled corticosteroids and long-acting beta2 agonist bronchodilator combinations (ICS-LABA). The acute attack of asthma was defined as the sudden onset of symptoms (wheezing, shortness of breath, coughing, chest tightness, etc.), or the exacerbation of the 
original symptoms, as well as the chronic persistent asthma was referred to weekly occurrence of symptoms at various frequencies and/or degrees (wheezing, shortness of breath, chest tightness, coughing, etc.) according to Guidelines for bronchial asthma prevent and management in China .In addition, we recruited 54 healthy volunteers with matching age, and sex serving as a normal control group. Exclusion criteria included: (1) Acute respiratory infections within 4 weeks, such as pneumonia, acute and chronic bronchitis, and tuberculosis; (2) Combined with other respiratory diseases, such as chronic obstructive pulmonary disease, bronchiectasis, lung cancer; (3) Severe liver and renal insufficiency and cardiac insufficiency; (4) Pregnant or lactating women; (5) Severe mental disorders; (6) The patients that have other diseases that might impact the results of the current study.

\section{Determination of FeNO level}

The FeNO detector, Sunvou-CA2122, (Share Ltd. Wuxi, China) was used to detect the FeNO. Before testing, all participants were informed the details of the procedure, and the detection of FeNO was strictly followed as per the manufacturer's instructions. The results were expressed in terms of parts per billion $\mathrm{ppb}\left(1 \mathrm{ppb}=1 \times 10^{-9} \mathrm{~mol} / \mathrm{L}\right)$.

\section{Lung function test}


Pulmonary function tests were performed using a System 7 device (Minato Medical Science Co., Osaka, Japan) according to standard of the American Thoracic Society (ATS)/European Respiratory Society (ERS) [23]. The gender, age, height, and weight of all participants were entered into the machine, and the expected value was automatically calculated. Body mass index (BMI) was calculated as weight $(\mathrm{kg})$ divided by height (cm) in squared meters. FVC, FVC\% predicted, FEV1, FEV1\% predicted, FEV1/FVC, and FEV1/FVC\% predicted were included for our analysis.

\section{Blood sample collection and analysis}

Fasting blood samples were drawn, centrifuged and serum was placed in plain polystyrene tubes on the same day. Serum samples were sent to the laboratory for storage at $-80{ }^{\circ} \mathrm{C}$. Peripheral blood eosinophil counts were performed using Sysmex XN2800 (Sysmex Co., Kobe, Japan) automatic blood cell analyzer on each participant. Serum concentrations of 14-3-3 $\beta$ in patients with asthma and controls were measured by were measured by ELISA kits according to the manufacturer's instructions (CUSABIO Life Science Ltd., Wuhan, China).

\section{Statistical analysis}

Statistical analysis was performed using SPSS software (version 20.0), Quantitative variables were presented as mean (standard deviation (SD)) 
or as the median and $25^{\text {th }}-75^{\text {th }}$ percentiles (interquartile range (IQR)). Categorical variables were presented as frequencies and percentages. Distribution normality was established by the Shapiro-Wilk normality test. Differences of sex between different groups were tested by chi-square test. To compare more than 2 groups, the one-way analysis of variance (ANOVA) for normally distributed data (such as age) and Kruskal-Wallis test followed by the Mann-Whitney U test (if a statistical difference was observed for non-normally distributed variables) were used to determine whether statistical significance existed across the groups. The relationship of $14-3-3 \beta$ to clinical indicators was assessed using Spearman's rank correlation coefficient. Receiver-operating characteristic (ROC) curves analysis was performed to evaluate the diagnostic utility of serum 14-3-3 $\beta$. Significance was achieved when $P<0.05$ for all tests.

\section{Results}

\section{Clinical characteristics and clinical indicators for all participants}

This case control study included 104 asthmatic patients: 54 cases were in acute attack group of asthma with age range between 19 and 66 years with a median of 45 years; 23 of them (43\%) were females and 50 cases were in chronic persistent group of asthma with age range between 18 and 66 years with a median of 45 years; 33 of them (66\%) were females. 54 cases were in normal control group aged between 18 and 64 years with a median of 
37, which included 30 females (56\%). Clinical characteristics (age, gender, and BMI) and clinical indicators (FeNO, eosinophil count, FVC, FVC\% predicted, FEV1, FEV1\% predicted, FEV1/FVC, and FEV1/FVC\% predicted) for all participants are provided in Table 1. There was no significant difference in gender and age between the each group $(P>0.05)$.

\section{Serum 14-3-3 $\beta$ expression in asthmatic subgroup and control group}

There was a statistically highly significant increase in the Median (IQR) $14-3-3 \beta$ levels in the acute attack group of asthma $[41.18 \mathrm{ng} / \mathrm{ml}(33.06-$ 51.76)] than in the normal control group [24.99 $\mathrm{ng} / \mathrm{ml}(17.42-29.91)], \mathrm{H}=$ $7.46, P<0.001$, and the chronic persistent group of asthma $[25.88 \mathrm{ng} / \mathrm{ml}$ (21.03-34.55)], $\mathrm{H}=5.91, P<0.001$, however, it was that exist no statistical heterogeneity with regard to serum level of $14-3-3 \beta$ between the chronic persistent group of asthma and the normal control group $(P>0.05)$, as shown in Table 1 and Fig. 1.

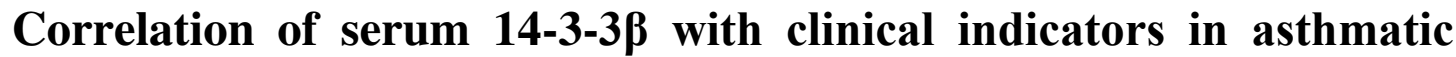

\section{subgroup}

The correlation matrices presented in Table 2 illustrate the relationship between the levels of serum 14-3-3 $\beta$ and clinical indicators in the acute attack group of asthma and the chronic persistent group of asthma, respectively. As expected, the levels of serum 14-3-3 $\beta$ was positively 
linked to FENO (r=0.292, $P=0.032)$ and peripheral blood eosinophil count $(\mathrm{r}=0.328, P=0.016)$, and was negatively related to FEV1/FVC $(\mathrm{r}=-0.293$, $P=0.031)$ and $\mathrm{FEV} 1 / \mathrm{FVC} \%$ predicted $(\mathrm{r}=-0.299, P=0.028)$ in the acute attack group of asthma, as shown in Fig. 2A-D. Furthermore, the levels of serum 14-3-3 $\beta$ was also negatively associated with FEV1 ( $r=-0.297$, $P=0.036)$ in the chronic persistent group of asthma, as shown in Fig. 2E. However, correlation analyses of serum 14-3-3 $\beta$ concentration with FENO, peripheral blood eosinophil count, FVC, FVC\% predicted, FEV1/FVC and FEV1/FVC\% predicted were not significant in the chronic persistent group of asthma. Furthermore, non-significant correlations were found among serum 14-3-3 $\beta$ concentration with FVC, FVC\% predicted, FEV1 and FEV1\% predicted in the acute attack group of asthma.

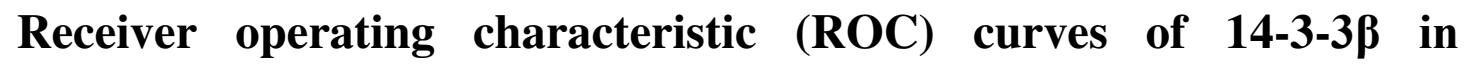
asthmatic subgroup

ROC curve analysis comparing acute attack group of asthma with normal control group demonstrated a significant $(P<0.001)$ AUC of $0.90(95 \% \mathrm{CI}$, 0.85-0.96), however, ROC curve analysis comparing chronic persistent group of asthma with normal control group demonstrated a no significant $(P>0.05)$ AUC of 0.60 (95\% CI, 0.49-0.70), as shown in Fig. 3 and Table

3. When the cut off value was $29.70 \mathrm{ng} / \mathrm{ml}$, the ROC curve yielded a sensitivity of $92.6 \%$, a specificity of $75.9 \%$, a positive likelihood ratio 
(+LR) of 3.84, negative likelihood ratio (-LR) of 0.10 and a Youden index of 0.69 in acute attack group of asthma.

\section{Discussion}

Asthma is a serious global health problem affecting all age groups, with increasing prevalence in many developing countries, rising treatment costs, and a rising burden for patients and the community [3, 24, 25]. Currently, diagnosis and treatment of asthma are often based on symptoms and lung function test results. However, these may not be able to predict future exacerbation. In addition, many primary care facilities are not equipped with spirometry to perform the necessary tests. Therefore, improvement of the serum diagnostic level of asthma and early therapeutic intervention to prevent acute attacks are of great significance.

Some studies have found that 14-3-3 protein can regulate activation of T cell [26], generation of Th2 cytokine [17] and IgE class switching and antibody secretion of B cells [19] by interactions with target proteins. As far as we are aware, this is the first study to explore the features of changes in serum levels of 14-3-3 $\beta$ in patients with asthma. An increase in the serum concentration of $14-3-3 \beta$ in the acute attack group of asthma has been found in comparison with the control group, which indicate that 143-3 $\beta$ may participate in the development of acute attack of asthma together and have some value in monitoring the state and prognosis of acute attack of asthma. However, it was that exist no statistical heterogeneity with regard to serum level of 14-3-3 $\beta$ between the chronic persistent group of asthma and the normal control group, which may be associated with the chronic use of ICS-LABA in chronic persistent group of asthma, because 
one study show that in mice with eosinophilic meningitis dexamethasone can decrease the expression of 14-3-3 $\beta$ protein in the CSF and in brain meninges [27].

FeNO is a biomarker of Th2 inflammation and is reported to be associated with clinical control of eosinophilic inflammation and asthma $[28,29]$. In the present study there was significant difference in FENO levels between asthmatic patients and control groups with higher values in the former, which was consistent with previous studies of Shrestha and colleagues [30], and the levels of serum 14-3-3 $\beta$ was positively linked to FENO in acute attack of asthma, indicating that 14-3-3 $\beta$ may be related to the airway inflammation of acute attack of asthma. Eosinophils are pivotal cellular effectors in the Type 2 inflammatory pathway and are thought to play a major role in maintaining long-term inflammation in asthma [28, 31]. In this study, asthmatic patients showed significant differences in blood eosinophil counts compared to the control group, which was in agreement with evidence from some cross-sectional studies [31, 32]. Also, the levels of serum 14-3-3 $\beta$ was positively correlated with peripheral blood eosinophil count in acute attack of asthma. Further evidence highlighted that 14-3-3 $\beta$ may be related to the airway inflammation of acute attack of asthma. While, there exist no correlation among the levels of serum 14-3$3 \beta$ with FENO and peripheral blood eosinophil count in the chronic persistent group of asthma, which may be affected by ICS-LABA. In this study, asthmatic patients showed significant differences in FEV1, FEV1\% predicted, FEV1/FVC and FEV1/FVC\% predicted compared to the control group, which was in agreement with previous studies of Cowan and colleagues [33]. Also, the levels of serum 14-3-3 $\beta$ was negatively related 
to FEV1/FVC and FEV1/FVC\% predicted in the acute attack group of asthma and to FEV1 in chronic persistent group of asthma. These findings demonstrate that $14-3-3 \beta$ is associated with airflow obstruction and indicate that it may be an important risk factor for lung function decline in asthmatic patients.

ROC curve analysis comparing acute attack group of asthma with normal control group demonstrated a significant difference in AUC, but AUC was not significantly different in chronic persistent group of asthma comparing with normal control group. When the cutoff value was 29.70 $\mathrm{ng} / \mathrm{ml}$, the ROC curve yielded a sensitivity of $92.6 \%$, a specificity of $75.9 \%$, a positive likelihood ratio (+LR) of 3.84, negative likelihood ratio (-LR) of 0.10 and a Youden index of 0.69 in acute attack group of asthma, suggesting that $14-3-3 \beta$ might be as a novel marker for the diagnosis in acute attack of asthma.

Our study has several limitations. The sample size was relatively small to perform the necessary multi-factor analysis. A completely different longitudinal study is required to determine whether $14-3-3 \beta$ can be used as a novel marker for the diagnosis in acute attack of asthma. In addition, we are unable to frequently measure 14-3-3 $\beta$ levels during the study period, which inhibits our ability to determine the effects of clinical intervention on 14-3-3 $\beta$ expression changes. Therefore, further research is needed to clarify the practical application value of $14-3-3 \beta$ as a new biomarker in a clinical setting. 


\section{Conclusion}

An increase in the level of serum 14-3-3 $\beta$ protein may be associated with airway inflammation and impaired bronchial patency in the acute attack of asthma. The serum 14-3-3 $\beta$ protein can be used to distinguish between asthmatic patients with acute attack and healthy individuals and may become a potential biomarker in asthmatic patients with acute attack.

\section{Acknowledgements}

None.

\section{Authors' contributions}

Decai Wang was the main contributor for analyzing data and drafting the article; Lizong Rao was the main contributor for revising the article; Yalan Cui was the main participant for the determination of serum 14-3-3 $\beta$; Tingguo Tang, Haiming Huang, and Ting Yuan were the main participant for the collection of blood samples; Biwen Mo was the main provider for the funding of this study. All authors read and approved the final manuscript.

\section{Funding}

This study was supported by the National Natural Science Foundation of 
China (81760008 and 81460005), the Guangxi Natural Science Foundation Program (2018GXNSFDA281041), and the High Level of Innovation Team and Outstanding Scholars Program in Colleges and Universities in Guangxi.

\section{Availability of data and materials}

All datasets used and/or analyzed during the current study are available from the corresponding author on reasonable request.

Ethics approval and consent to participate

The present study was approved by the Ethics Committee of Affiliated Hospital of Guilin Medical University (2021GLMU1AYJS055). Written informed consent was obtained from each participants.

\section{Consent for publication}

Not applicable.

\section{Competing interests}

The authors declare that they have no competing interests.

\section{References}

1. Lambrecht B N, Hammad H, Fahy J V. The Cytokines of Asthma. Immunity. 2019; 50: 975-91.

2. Kubysheva N, Boldina M, Eliseeva T, Soodaeva S, Klimanov I, Khaletskaya A, et al. 
$\alpha$ Relationship of Serum Levels of IL-17, IL-18, TNF-, and Lung Function Parameters in Patients with COPD, Asthma-COPD Overlap, and Bronchial Asthma. Mediat Inflamm. 2020; 2020: 4652898.

3. King-Biggs M B. Asthma. Ann Intern Med. 2019; 171: ITC49-ITC64.

4. Ebmeier S, Thayabaran D, Braithwaite I, Bénamara C, Weatherall M, Beasley R. Trends in international asthma mortality: analysis of data from the WHO Mortality Database from 46 countries (1993-2012). Lancet. 2017; 390: 935-45.

5. Xing Y C, Chen Q. Serum BPI as a novel biomarker in asthma. Allergy Asthma Clin Immunol. 2020; 16: 50.

6. Moore B. Specific acidic proteins of the nervous system. P Physiol Biochem Aspects Nerv Integr. 1967; 343-59.

7. Maksymowych W P, Naides S J, Bykerk V, Siminovitch K A, Van Schaardenburg D, Boers M, et al. Serum $14-3-3 \eta$ is a novel marker that complements current serological measurements to enhance detection of patients with rheumatoid arthritis. J Rheumatol. 2014; 41: 2104-13.

8. Cau Y, Valensin D, Mori M, Draghi S, Botta M. Structure, function, involvement in diseases and targeting of 14-3-3 proteins: an update. Curr Med Chem. 2018; 25: 5-21.

9. Aghazadeh Y, Papadopoulos V. The role of the 14-3-3 protein family in health, disease, and drug development. Drug Discov Today. 2016; 21: 278-87.

10. Abdrabou A, Brandwein D, Wang Z. Differential Subcellular Distribution and Translocation of Seven 14-3-3 Isoforms in Response to EGF and During the Cell Cycle. Int J Mol Sci. 2020; 21: 318

11. Inamdar S, Lankford C, Laird J, Novbatova G, Tatro N, Whitmore S, et al. Analysis of 14-3-3 isoforms expressed in photoreceptors. Exp Eye Res. 2018; 170: 108-16.

12. Berg D, Holzmann C, Riess O. 14-3-3 proteins in the nervous system. Nat Rev Neurosci. 2003; 4: 752-62.

13. Cau Y, Fiorillo A, Mori M, Ilari A, Botta M, Lalle M. Molecular Dynamics Simulations and Structural Analysis of Giardia duodenalis 14-3-3 Protein-Protein Interactions. J Chem Inf Model. 2015; 55: 2611-22.

14. Diallo K, Oppong A, Lim G. Can 14-3-3 proteins serve as therapeutic targets for the treatment of metabolic diseases? Pharmacol Res. 2019; 139: 199-206.

15. Fan X, Cui L, Zeng Y, Song W, Gaur U, Yang M. 14-3-3 proteins are on the crossroads of cancer, aging, and age-related neurodegenerative disease. Int J Mol Sci. 2019; 20: 3518.

16. Guan S-Z, Yang Y-Q, Bai X, Wang Y, Feng K-Q, Zhang H-J, et al. Serum 14-3-3ๆ Could Improve the Diagnostic Rate of Rheumatoid Arthritis and Correlates to Disease Activity. Annals of Clinical \& Laboratory Science. 2019; 49: 57-62.

17. Cascio S, Medsger Jr T A, Hawse W F, Watkins S C, Milcarek C, Moreland L W, et al. 14-3$3 z$ sequesters cytosolic T-bet, upregulating IL-13 levels in TC2 and CD8+ lymphocytes from patients with scleroderma. J Allergy Clin Immun. 2018; 142: 109-19. e6.

18. Kistner A, Bigler M B, Glatz K, Egli S B, Baldin F S, Marquardsen F A, et al. Characteristics of autoantibodies targeting 14-3-3 proteins and their association with clinical features in newly diagnosed giant cell arteritis. Rheumatology. 2017; 56: 829-34.

19. Li F, Huang Y, Huang Y Y, Kuang Y S, Wei Y J, Xiang L, et al. MicroRNA-146a promotes IgE class switch in B cells via upregulating 14-3-3 $\sigma$ expression. Mol Immunol. 2017; 92: 1809. 
20. He S J, Chen Y, Tong X S, Yan W H, Jiang Z F. Effect of Budesonide on 14-3-3 Protein and 14-3-3 $\beta$ mRNA Expression in Asthmatic Rat Lung Tissue. Journal of Pediatric Pharmacy. 2016; 22: 5-7.

21. Global Initiative for Asthma. Global strategy for asthma management and prevention. Available from: wwwginasthmaorg. 2018.

22. Asthma Group of Respiratory Disease Branch of Chinese Medical Association. Guidelines for bronchial asthma prevent and management(2016 edition). Chin J Tuberc Respir Dis. 2016; 39: 675-97.

23. Miller M, Hankinson J, Brusasco V, Burgos F, Casaburi R, Coates A, et al. Standardisation of spirometry. Eur Respir J. 2005; 26: 319-38.

24. Huang K, Yang T, Xu J, Yang L, Zhao J, Zhang X, et al. Prevalence, risk factors, and management of asthma in China: a national cross-sectional study. Lancet. 2019; 394: 407-18.

25. GBD 2015 Chronic Respiratory Disease Collaborators. Global, regional, and national deaths, prevalence, disability-adjusted life years, and years lived with disability for chronic obstructive pulmonary disease and asthma, 1990-2015: a systematic analysis for the Global Burden of Disease Study 2015. Lancet Respir Med. 2017; 5: 691-706.

26. Meller N, Liu Y-C, Collins T L, Bonnefoy-Berard N, Baier G, Isakov N, et al. Direct interaction between protein kinase $\mathrm{C}$ theta (PKC theta) and 14-3-3 tau in $\mathrm{T}$ cells: 14-3-3 overexpression results in inhibition of PKC theta translocation and function. Mol Cell Biol. 1996; 16: 5782-91.

27. Tsai H, Chen Y, Yen C, Chung L, Wann S, Lee S, et al. Dexamethasone Downregulates Expressions of 14-3-3 $\beta$ and $\gamma$-Isoforms in Mice with Eosinophilic Meningitis Caused by Angiostrongylus cantonensis Infection. Korean J Parasitol. 2019; 57: 249-56.

28. Robinson D, Humbert M, Buhl R, Cruz A, Inoue H, Korom S, et al. Revisiting Type 2-high and Type 2-low airway inflammation in asthma: current knowledge and therapeutic implications. Clin Exp Allergy. 2017; 47: 161-75.

29. Wang K, Verbakel J, Oke J, Fleming-Nouri A, Brewin J, Roberts N, et al. Using fractional exhaled nitric oxide to guide step-down treatment decisions in patients with asthma: a systematic review and individual patient data meta-analysis. Eur Respir J. 2020; 55: 1902150.

30. Shrestha S, Drews A, Sharma L, Pant S, Shrestha S, Neopane A. Relationship between total serum immunoglobulin E levels, fractional exhaled breath nitric oxide levels and absolute blood eosinophil counts in atopic and non-atopic asthma: a controlled comparative study. J Breath Res. 2018; 12: 026009.

31. Hancox R J, Pavord I D, Sears M R. Associations between blood eosinophils and decline in lung function among adults with and without asthma. Eur Respir J. 2018; 51: 1702536.

32. Wagener A H, De Nijs S B, Lutter R, Sousa A R, Weersink E J, Bel E H, et al. External validation of blood eosinophils, $\mathrm{FE}(\mathrm{NO})$ and serum periostin as surrogates for sputum eosinophils in asthma. Thorax. 2015; 70: 115-20.

33. Cowan D, Taylor D, Peterson L, Cowan J, Palmay R, Williamson A, et al. Biomarker-based asthma phenotypes of corticosteroid response. J Allergy Clin Immunol. 2015; 135: 877-83.e1. 
Figures

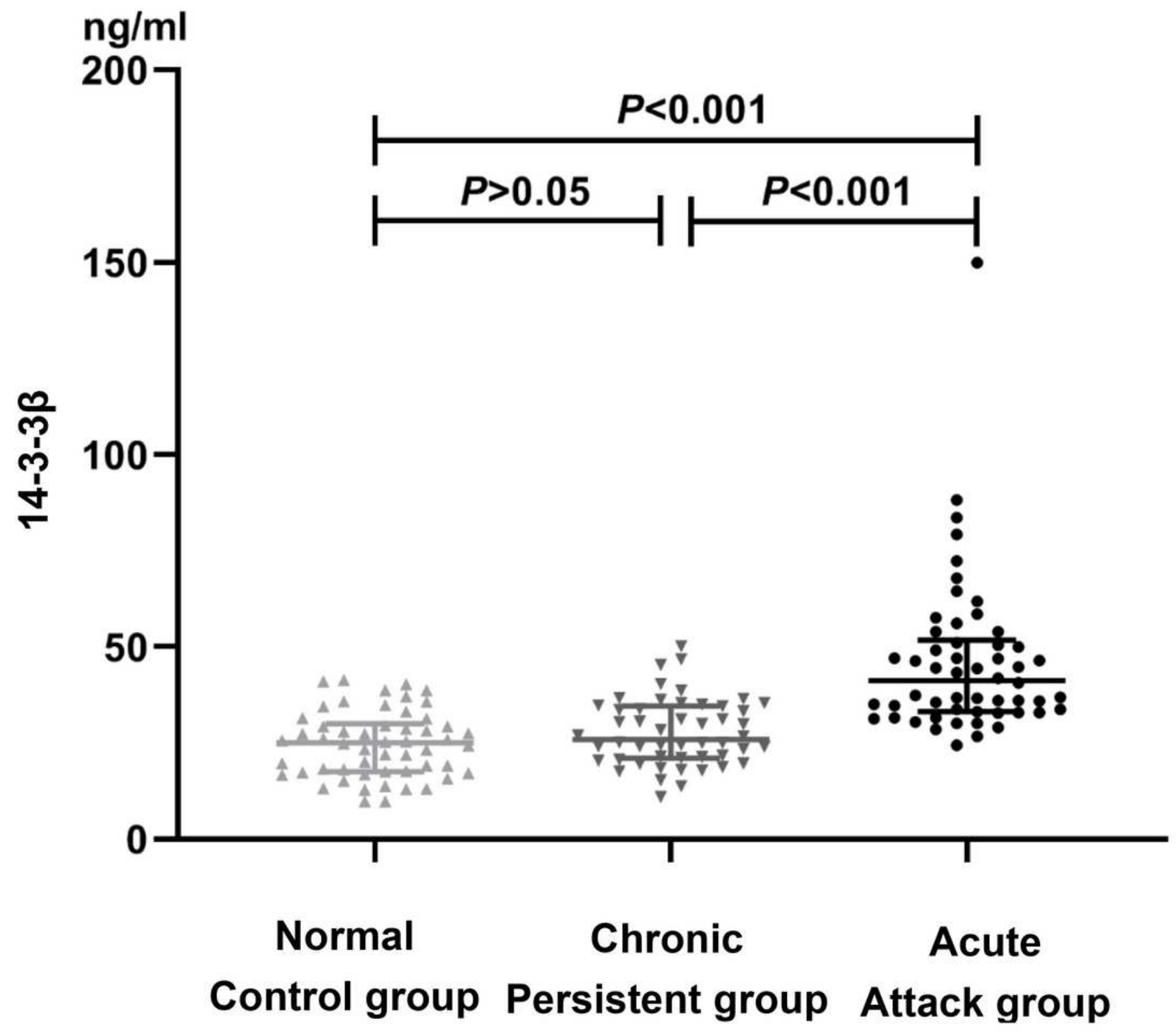

Figure 1

Comparison of serum 14-3-3 $\beta$ levels in normal control group and asthmatic subgroup. 

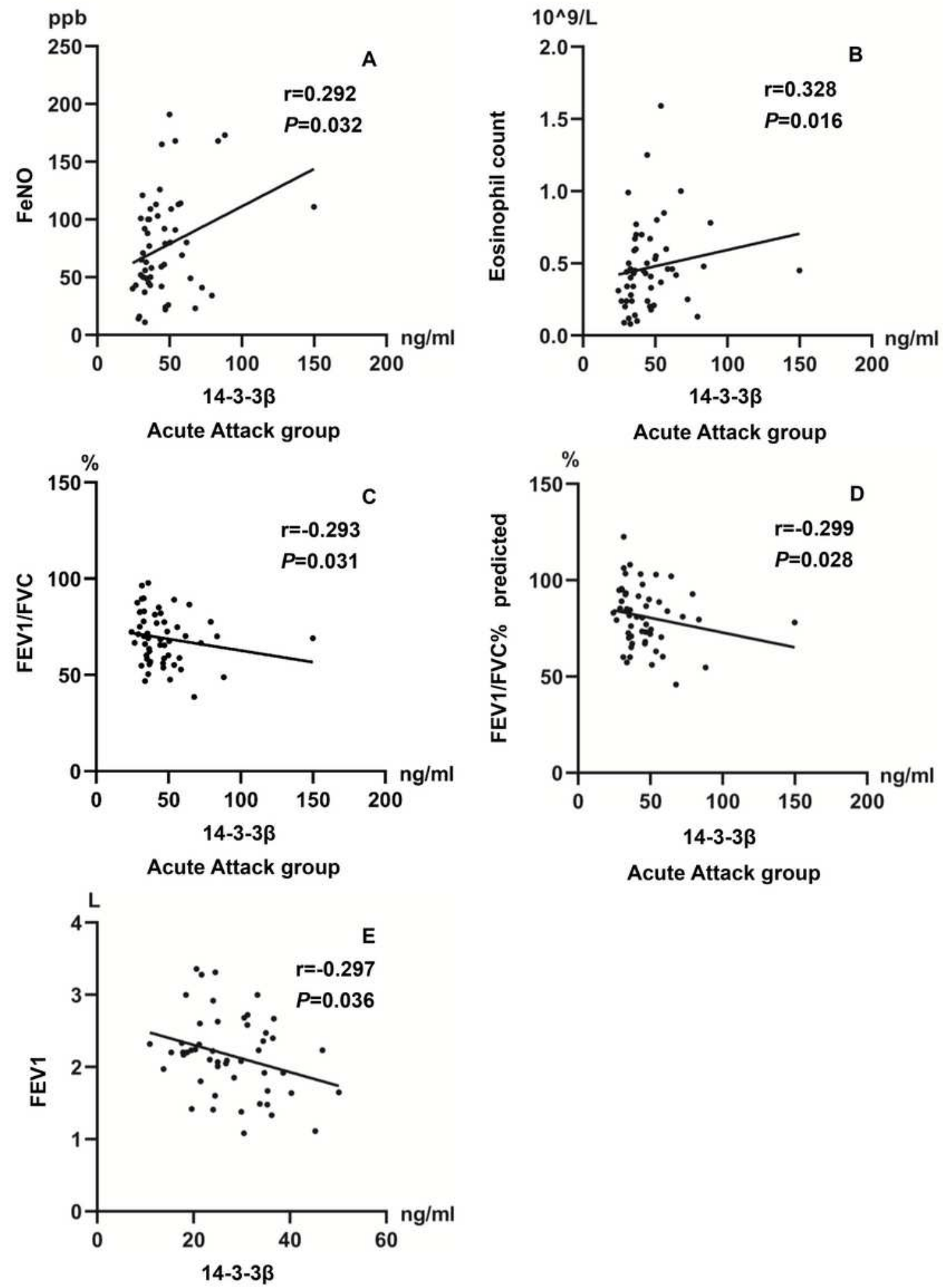

Chronic Persistent group

Figure 2

Correlation between serum 14-3-3 $\beta$ levels and clinical indicators in asthmatic subgroup. A-D. Correlation between 14-3-3 $\beta$ and FeNO; blood eosinophil count; FEV1/FVC; FEV1/FVC\% predicted in acute attack group of asthma; E. Correlation between 14-3-3 $\beta$ and FEV1 in chronic persistent group of asthma. 

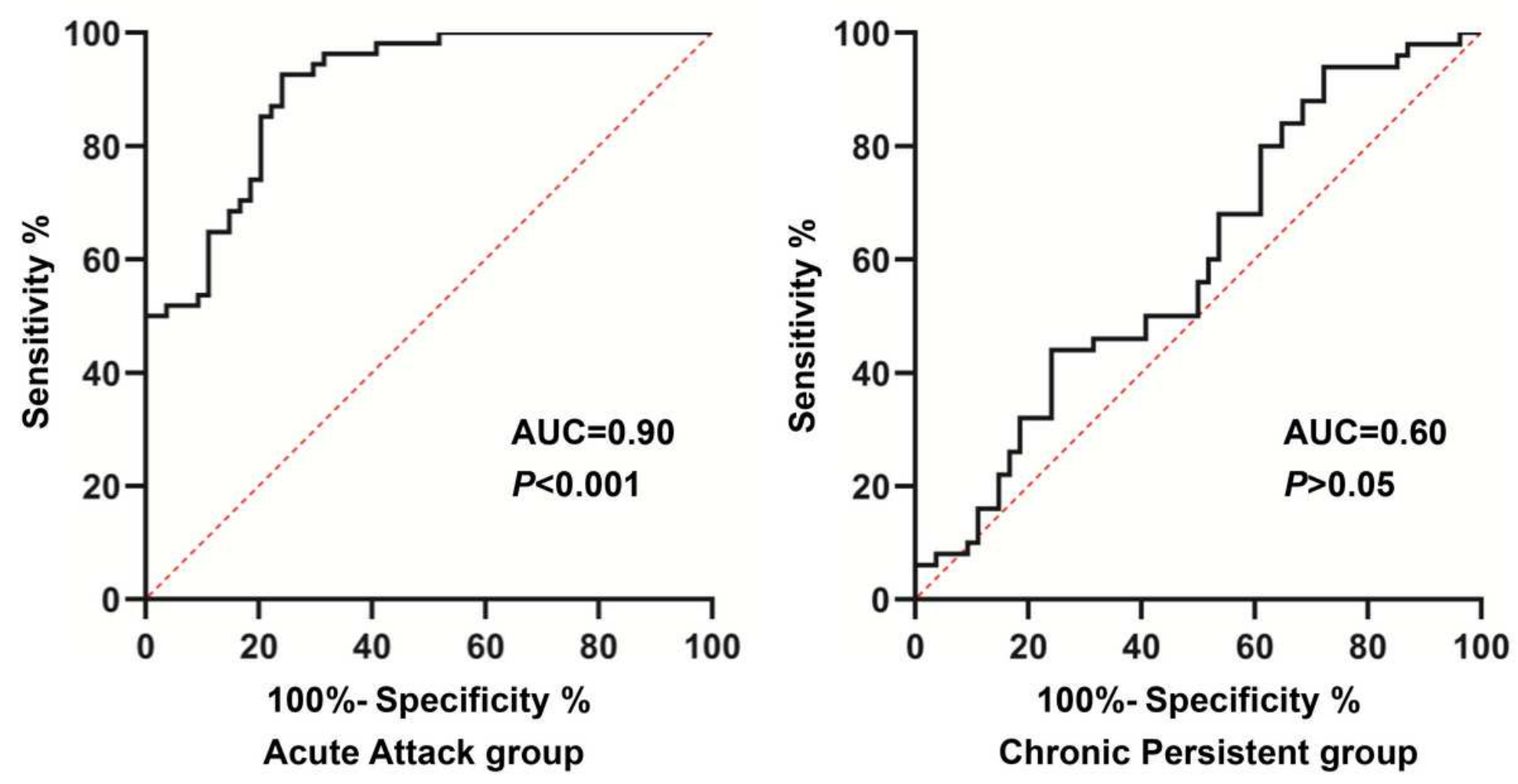

Figure 3

Receiver operating characteristic (ROC) curve for serum 14-3-3 $\beta$ levels comparing asthmatic subgroup with normal control group.

\section{Supplementary Files}

This is a list of supplementary files associated with this preprint. Click to download.

- table1.pdf

- table2.pdf

- table3.pdf 